[Contribution from the Laboratory of Agricultural, Chemistry, Ohio State UNIVERSITY.]

\title{
CASTOR BEAN LIPASE, ITS PREPARATION AND SOME OF ITS PROPERTIES.
}

By D. E. HALEX AND J. F. LYMAN.

Received August 25, 1921.

In the extended studies on lipases by Falk ${ }^{1}$ and his associates little attention has been given to the most favorable conditions for the preparation and activity of the enzyme material. Taylor, ${ }^{2}$ von Hoyer, ${ }^{3}$ Jalander, ${ }^{4}$ Tanaka, ${ }^{5}$ Barton $^{6}$ and others have proposed methods of preparing and using castor bean lipase. In an attempt to study the action of castor bean lipase on various esters we encountered difficulties, first, in obtaining an active, approximately fat-free preparation which would act as a good emulsifying agent for water and fats; and second, in adjusting the conditions so that rapid and nearly complete hydrolysis of the fat might occur.

We have found that it is comparatively easy to overcome both of these difficulties; but, as far as we have been able to find, no one has yet described methods that can be followed with entire satisfaction.

\section{Preparation of Lipase Material from the Castor Bean.}

An attempt was made to modify the procedure of von Hoyer with the hope of obtaining a very active lipase, free from fat and cell residues. Lipase "cream" was prepared by the method described by von Hoyer. ${ }^{3}$ This was dried at room temperature and extracted with ethyl ether. The small residue insoluble in ether is designated "cream residue." A sediment which settled from the castor bean "milk" was also separated, dried and extracted with ether. The main portion, representing the cell walls and other insoluble constitutents of the beans, was likewise dried and extracted. There were thus three fractions: (1) fat-free residue from castor bean "cream," (2) fat-free sediment from castor bean "milk," and (3) fat-free residue of cellular materials not emulsified or dissolved by grinding and mixing the beans with water. A comparative test for lipolytic activity showed that Fraction 3 was high in lipase, while the small residue from the "cream" contained relatively little enzyme.

The materials were mixed in test-tubes in the amount and order named; 0.1 g. of lipase preparation, $1.0 \mathrm{~g}$. of olive oil and $0.6 \mathrm{cc}$. of $0.1 \mathrm{~N}$ acetic acid. The tests were incubated at $38^{\circ}$ for 12 hours and the free fatty acids then determined by titration against $0.1 \mathrm{~N}$ alcoholic sodium hydroxide using phenolphthalein as indicator. Before making the titrations the contents of the tubes were transferred to flasks by means

${ }^{1}$ Falk and Nelson, This Journal, 34, 735 (1912).

a Taylor, J. Biol. Chem., 2, 87 (1906).

a von Hoyer, Z. physiol. Chem., 50, 414 (1906).

Jalander, Biochem. Z., 36, 435 (1911).

- Tanaka, J. Coll. Eng. Imp. Univ. Tokyo, 5, 125 (1912).

6 Barton, This Journal, 42, 620 (1920). 
TABLE I.

Relative Lipolytic Activity OF Fat-FREE Residue from von Hoyer's Castor Bean "Cream," Sediment from Castor Bean "Milk" and Main Insoluble Residue.

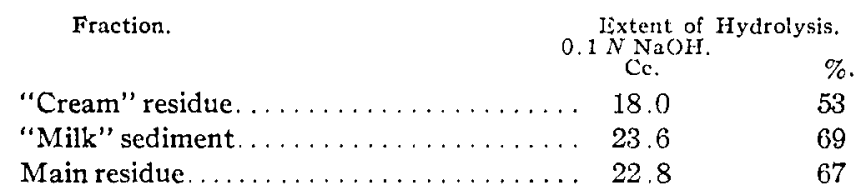

of $50 \mathrm{cc}$. of neutral alcohol. Without the alcohol satisfactory results cannot be obtained on account of hydrolysis of sodium soaps formed in the titration and also because of the insolubility of the fatty acids in water. All tests reported in this paper were made in duplicate. Corrections were made for reagents and "blank" digestions.

Since the fat-free residue from the "cream" was small and its lipolytic action relatively low, this material does not seem promising. The main residue is easily obtained in quantity and has a good degree of activity. Its physical condition is likely to be unfavorable, however, because on drying there is a tendency for it to assume a tough horny consistency; and in this condition it does not mix readily with water, nor act as a good emulsifying agent. Alcohol and acetone were tried as dehydrating agents. While they gave a lipase material of good physical condition, the lipolytic action was entirely destroyed or lost in the process. It is probable that alcohol and acetone are destructive to castor bean lipase. ${ }^{4}$

The most satisfactory lipase material that we have prepared, judging by its physical condition and by its activity in hydrolyzing fats, was obtained by a slight modification of 'Taylor's ${ }^{2}$ method. Castor beans ${ }^{7}$ are shelled by cracking the hull with a small hammer and peeling off the outer covering of the seed by hand. The kernels are ground as finely as possible in a food chopper, and extracted in a Soxhlet extractor with petroleum cther. The extracted material is then passed through a 40-mesh sieve. We have found low-boiling petroleum ether more satisfactory as a solvent for this purpose than ethyl ether, although the latter can be used. We have not attempted to concentrate or isolate the lipase from the fat-free kernels.

\section{The Solubility of Castor Bean Lipase in Ether and in Ether-Fat Mixtures.}

'Taylor ${ }^{2}$ states that lipase of castor beans is insoluble in ethyl ether but that it dissolves in a mixture of ether and fat. 'The following experiment tends to verify this statement. Four portions of $3 \mathrm{~g}$. each of extracted bean powder were treated as follows: (1) $25 \mathrm{cc}$. of olive oil was added; (2) $25 \mathrm{cc}$. of olive oil and $100 \mathrm{cc}$. of ethyl ether werc added; (3) $100 \mathrm{cc}$. of ethyl ether was added; (4) nothing was added. All were allowed to stand at room temperature for 4 days. 'The solvents were then removed by decantation and filtration and all 4 residues extracted with petroleum

7 The castor beans were donated by the Baker Castor Oil Co., N. Y. 
ether in a Soxhlet apparatus. The following table shows the loss of activity when the lipase material remained in contact with fat or with fat and ether.

TABLE II.

Loss of Lipolytic Activity on Treating Fat-FREE Castor BEan Powder with FAT, OR ETHER AND FAT.

In all of these digestion trials $0.1 \mathrm{~g}$. of lipase material, $1.0 \mathrm{~g}$. of olive oil and $0.6 \mathrm{cc}$. of $1 \%$ acetic acid were mixed and incubated at $38^{\circ}$ for 24 hours.

Extraction with

Hydrolytic Activity.
$0.1 \mathrm{~N} \mathrm{NaOH}$. Fat digested.
$\mathrm{Cc}$.

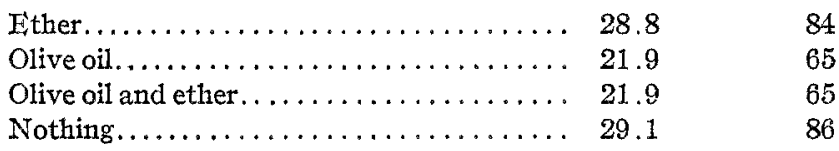

The Activation of Castor Bean Lipase by Acid.

It was noted by von Hoyer $^{3}$ that freshly prepared castor bean lipase material does not begin to hydrolyze fats until after the appearance of a soluble acid in the mixture. He postulated the occurrence of a lactic acid producing enzyme in castor beans, the acid being necessary to convert the inactive zymogen of the beans into active lipase. Tanaka ${ }^{5}$ has proposed a method of activating castor bean lipase in which the bean cake, from which the oil has been expressed, is treated with dilute acid, washed free from acid and dried. Such material can be stored indefinitely and is active without further addition of acid. Kita's statement ${ }^{8}$ that the active enzyme is unstable in acid solution in the absence of fats is borne out by our experience. An attempt to activate the zymogen in ether extracted castor beans by Tanaka's method resulted in complete loss of activity. It was possible to activate the zymogen of unextracted beans as shown by the following experiment. Fifty g. of ground castor bean kernels was mixed with $150 \mathrm{cc}$. of $1 \%$ acetic acid and allowed to stand for 3 days at room temperature. The mixture was filtered, washed with water, dried at room temperature, and extracted with petroleum ether. The activity of the resulting powder was checked, with and without the addition of acid, against ether-extracted castor bean powder.

TABLE III.

The Activation of Castor Bean Lipase by Actd.

\begin{tabular}{|c|c|c|c|}
\hline Treatment. & & $\begin{array}{l}\text { Extent of F } \\
0.1 N \mathrm{NaOH} \text {. }\end{array}$ & \\
\hline Unactivated powder & & 0.37 & $\begin{array}{l}7 . \\
2\end{array}$ \\
\hline & $\ldots$. & 27.6 & 81 \\
\hline Activated powder + & $+\mathrm{H}_{2} \mathrm{O} \ldots \ldots \ldots \ldots \ldots$ & $\begin{array}{l}25.2 \\
27.4\end{array}$ & 74 \\
\hline
\end{tabular}

In our experiments we found that the order in which the materials are mixed in making up a digestion mixture is a matter of great importance.

s Kita, J. Chem. Ind. Tokyo, 21, 1-5 (1918). 
If the acid is added to the enzyme material before the oil a complete loss of lipase is likely to occur. Barton ${ }^{6}$ notes the better emulsion obtained when the oil is added to the enzyme material before the acid is introduced. This is undoubtedly an important point, but the danger of destroying the active enzyme by acid in the absence of fat is a more serious consideration.

\section{The Concentration of Acid Most Favorable to the Hydrolysis of Fats by Castor Bean Lipase.}

Although many experiments have been performed to determine the effect of acid on castor bean lipase we are not aware that the most favorable concentration, expressed in terms of actual acidity, has been determined. Barton's ${ }^{6}$ conclusion that castor bean lipase has its optimum activity toward the three substances, lard, olive oil and ethyl butyrate at approximately $0.6 \%$ concentration of hydrochloric acid seems quite unjustified by his own data and in entire conflict with our results. We have repeated some of Barton's experiments and, under the conditions of his tests, find little if any activity. In view of the uncertainty of the accuracy of corrections made for "blank" experiments, small digestion values appear to us to have little significance. This is borne out by the fact that negative values were obtained in many of Barton's experiments. Table IV gives the lipolytic activity of our preparation at the acid concentrations used by Barton and for comparison his results obtained under similar conditions.

TABLE IV.

EFFect of Vartous Concentrations of Hydrochloric Acid on Castor Bean LIPASE IN HydRoLiyzing OLIVE OIL.

In each experiment $0.2 \mathrm{~g}$. of lipase powder, $0.3 \mathrm{cc}$. of olive oil and $25 \mathrm{cc}$. of the acid called for were mixed and inctubated at $38^{\circ}$ for 24 hours.

$\begin{array}{ccc}\begin{array}{c}\text { Concentration } \\ \text { HCl added. } \\ \% .\end{array} & \begin{array}{c}\text { Amount of Hydrolysis Produced in Terms of } 0.1 \mathrm{~N} N \mathrm{NaOH} . \\ \text { As found by Barton. } \\ \text { Cc. }\end{array} \\ 0.0 & \mathrm{Cc} & 0.2 \\ 0.1 & 0.7 & 2.0 \\ 0.2 & 0.8 & 1.2 \\ 0.3 & 0.7 & 1.1 \\ 0.4 & 0.5 & 1.3 \\ 0.5 & 0.6 & 1.6 \\ 0.6 & 0.7 & -0.8 \\ 0.7 & 0.5 & -0.8 \\ 0.8 & 0.5 & -0.1 \\ 0.9 & 0.5 & -0.5 \\ 1.0 & 0.5 & -0.5\end{array}$

It occurred to us that Barton overstepped the optimum acidity in the lowest acidity, viz., $0.1 \%$ of hydrochloric acid, that he used, since in his most active mixtures the amount of fat hydrolysis was very low. Accordingly we made the following experiment to find the effect of varying the concentration of acid between 0.0 and $0.1 \%$. At the same time we 
made another series of tests in which we added the same strengths of acid but used much smaller volumes. The following table shows the results.

TABLE V.

EFFect OF Various CONCENTRations of Hydrochloric ACID ON Castor Bean LIPASE IN HYDROLYZING OLIVE OIL.

In Series A $0.2 \mathrm{~g}$. of lipase powder, $0.3 \mathrm{cc}$. of olive oil and $25 \mathrm{cc}$. of acid were mixed as described by Barton. In Series B, $0.1 \mathrm{~g}$. of lipase, $1.0 \mathrm{~g}$. of olive oil and $0.6 \mathrm{cc}$. of acid were mixed. The essential difference in the two series is the amount of acid used.

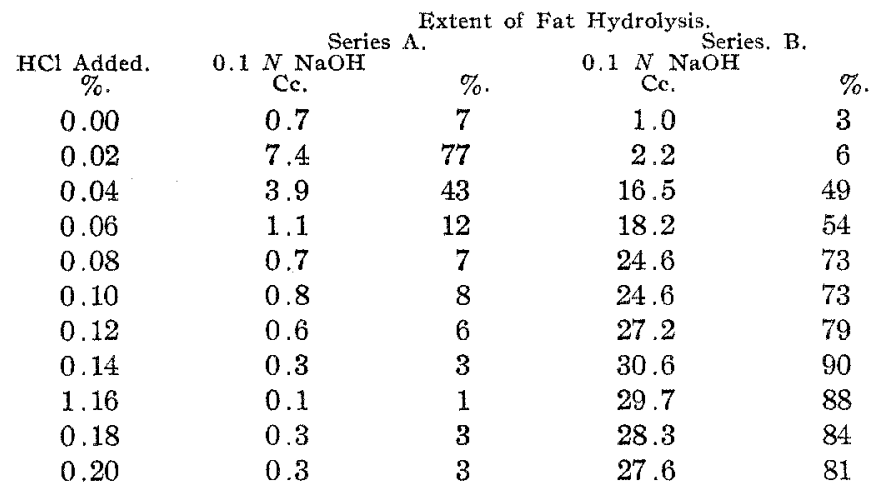

Table $\mathrm{V}$ shows that whether large or small volumes of acid are used the enzyme shows its maximum activity at a certain concentration and then falls off, rapidly when the volume of acid is large and slowly when it is small. At a concentration of hydrochloric acid of $0.1 \%$ in Series A there was practically no digestion. The slight hydrolysis indicated is probably without significance and within the limit of experimental error. It must be remembered that the amount of fat used in this series was small, only $0.3 \mathrm{cc}$, and the necessary corrections for blanks, etc., were relatively large. It is to be expected that the proteins and salts of the lipase powder would show a buffer effect, and hence that the actual concentration of acid in two tubes containing equal amounts of lipase material to which different volumes of the same strength acid had been added would be different. From Table V it appears that the optimum activity in Series $A$ is about $0.02 \%$ of hydrochloric acid, while in Series B the optimum concentration is at 0.14 . It was suspected that the actual hydrogen-ion concentrations in these two mixtures were about the same. A determination was made by the colorimetric method of Clark and Lubs ${ }^{9}$ as follows. Lipase powder and hydrochloric acid were mixed in the following proportions: (1) $0.2 \mathrm{~g}$. of lipase to $25 \mathrm{cc}$. of $0.02 \%$ hydrochloric acid and (2) $0.1 \mathrm{~g}$. of lipase to $0.6 \mathrm{cc}$. of $0.14 \%$ hydrochloric acid The mixtures were allowed to stand a few minutes, filtered and the hydrogen-ion concentration of the filtrate determined. Mixture 1 had a hydrogen-ion concentration of $1.8 \times 10^{-5}$;

9 Clark and Lubs, $J$. Bact., 2, 1 (1917). 
Mixture $2,0.9 \times 10^{-5}$. The optimum acidity for castor bean lipase activity, therefore, is close to $\mathrm{C}_{\mathrm{H}}+1 \times 10^{-5}$. This is about the same as that found for gastric lipase by Davidsohn, ${ }^{10}$ viz., $10^{-4}$ to $10^{-5}$. When organic acids, that ionize comparatively little, are used less care need be taken to adjusting the amount of acid to the enzyme. Both acetic and lactic acids can be used with good results over a fairly wide range of percentage concentration.

\section{The Action of Castor Bean Lipase on Hard Fats.}

Fats with high melting points, obviously, do not form emulsions with lipase material and water; hence it is not surprising that they show a low rate of hydrolysis. In order to overcome this difficulty we introduced various fat solvents into the digestion mixtures in the hope of getting better physical contact between enzyme and substrate and thus accelerating hydrolysis. Paraffine oil and ethyl ether were unsatisfactory, comparatively little digestion occurring when either was present. Petroleum ether can be added to advantage in the hydrolysis of an oil by lipase and with marked effect in the hydrolysis of a hard fat. Table VI shows the results obtained with and without petroleum ether.

\section{TABLE VI.}

Efeect of Petroleum Ether on the Hydrolysis of Fats by Castor Bean lipase. The proportions used in each digestion were $0.1 \mathrm{~g}$. of lipase powder, $0.2 \mathrm{~g}$. of fat and $0.6 \mathrm{cc}$. of $0.1 \mathrm{~N}$ acetic acid. One cc. of petroleum ether was added to the mixtures containing ether.

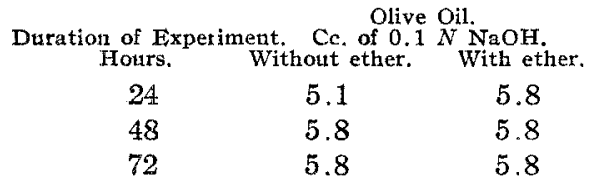

\begin{tabular}{cc}
\multicolumn{2}{c}{$\begin{array}{c}\text { Tallow. of } 0.1 \\
\text { Ne }\end{array}$ NaOH. } \\
Without ether. & With ether. \\
0.2 & 6.5 \\
0.2 & 6.6 \\
0.2 & 6.6
\end{tabular}

\section{Summary.}

A satisfactory method of preparing lipase material from castor beans is to extract the crushed, hull-free kernels with petroleum ether.

The lipase zymogen of castor beans appears to be somewhat soluble in fats or in a mixture of fat and ethyl ether. It is insoluble in ethyl ether in the absence of fats.

Lipase zymogen is activated by acid. The active enzyme is unstable and rapidly destroyed in an acid medium in the absence of fats. In the presence of fats the enzyme shows much greater stability.

The optimum hydrogen-ion concentration for castor bean lipase activity is about $1 \times 10^{-5}$. As acidity increases above this point lipolytic activity falls off. At a hydrogen-ion concentration of about $1 \times 10^{-3}$ activity stops entirely.

${ }^{10}$ Davidsohn, Biochem. Z., 49, 249 (1913). 
Petroleum ether added to a mixture of a hard fat, acid, water and castor bean lipase accelerates hydrolysis to a great extent. The hydrolysis of oils is similarly somewhat hastened.

Columbus, Ohro.

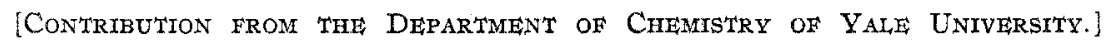

\section{RESEARCHES ON PYRIMIDINES. XCII. NEW METHODS OF IDENTIFYING THE PYRIMIDINE, THYMINE.}

\section{By Treat B. Johnson and Oskar Batdisch.}

Received August 29, 1921.

Of the three pyrimidines which have so far been found as products of hydrolysis of nucleic acids only two, namely, uracil (I) and cytosine (II), can be identified by means of characteristic color reactions. Wheeler and Johnson ${ }^{1}$ developed a delicate test for these two pyrimidines which<smiles>O=c1cc[nH]c(=O)[nH]1</smiles>

(I).<smiles></smiles>

(II).<smiles>CC(=O)NC1CON1</smiles>

(III).

is applied by first oxidizing them in aqueous solution with bromine and then treating the resulting solution with an excess of barium hydroxide. A characteristic purple color develops under such conditions, due to the formation of the barium salt of dialuric acid, which permits of the identification of these two pyrimidines when present in very small quantities. Thymine (III) or any pyrimidine of this type containing alkyl groups in Positions 4 or 5 of the pyrimidine ring fails to respond to this characteristic test.

On account of the important rôle which thymine plays in the chemical processes operating during the growth and destruction of the living cell, it is very important to have available also a characteristic color reaction for the detection of this pyrimidine. A color test which would permit the identification of thymine in the presence of uracil, cytosine and sugar would be of the greatest value in any investigation dealing with the constitution of nucleic acids. The basic properties of cytosine permit its separation from uracil and thymine, but up to the present time we have had no method of identifying small quatities of thymine in the presence of uracil and sugars.

We are able to announce in this paper the discovery of color reactions which are as characteristic for thymine as the dialuric acid reaction is for the identification of the pyrimidine uracil. We find that the thymine molecule is completely destroyed at ordinary temperature, when subjected

${ }^{1}$ Wheeler and Johnson, J. Biol. Chem., 3, 183 (1907). 